\title{
Indigenous Flaps in ENT: Our Experience
}

\author{
Manish Munjal ${ }^{1}$, Archana Arora ${ }^{1 *}$, Gopika Talwar ${ }^{1}$, Amanjot Kaur $^{1}$ and Tejinder ${ }^{2}$ \\ ${ }^{1}$ Deptt of ENTHNS, Dayanand Medical college and Hospital, Ludhiana, Punjab, India \\ ${ }^{2}$ Dhillon ENT Research Centre, Khanna, Ludhiana, Punjab, India
}

\section{ABSTRACT}

The nose is undoubtedly an important facial feature. The rhinologic surgeon with interest in external nasal soft tissue surgery, oncologic or otherwise, may often require reconstruction of a soft tissue defect, from the medial canthus to the nasal ala laterally, to the nasal tip medially. The coverage needs tissues which resemble the adjoining skin texture and have a thickness which would fill the defect appropriately without appearing as a separate patch and upset the patient psychologically. Therefore we utilized local rotation and advancement flaps for the reconstruction of facial defects. Experience with these flaps is being shared.

Keywords: Nasolabial Flap, Forehead Transposition Flap, Rintala Flap

\section{Introduction}

The history of nasal reconstruction parallels that of plastic surgery. It was begun by Sushruta in India during 600-700 $\mathrm{BC}$ [1]. The first procedure that was used for the nasal reconstruction was the midline forehead flap. The present era reconstructive surgeon now has a number of options in his armamentarium like local tissue from the nose, cheek, and forehead and also grafts from the nasal septum, ear, rib, hip, and calvaria [2].

As ENTHNS surgeons, we evaluate lesions which require reconstruction after excision and using simple techniques we can do without the assistance of plastic surgery colleagues. Some simple flaps shall be discussed here.

Being a defining feature of the face, the nose is arguably the most prominent aspect. It is a composite structure composed of skin, mucosal lining, cartilage, muscle, subcutaneous tissue, septum, and bone. Nasal reconstruction is thus a very challenging job for most plastic and reconstructive surgeons.

Commonly employed local flaps for defects along the medial canthus, nasal dorsum and nasal ala include the Nasolabial flap, Forehead transposition flap and Rintala flap which use the principles of VY advancement and Burows triangle. Our experience with these flaps is being described.

\section{Nasolabial flap}

A robust superiorly based myocutaneous flap pedicled on the facial artery, the nasolabial flap is an excellent choice in reconstruction of the nasal alar subunit, nasal tip, dorsum, soft triangle, and partial alar defects or single-stage reconstruction of oral cavity defects. Certain qualities make this flap ideal for nasal reconstruction. The color, skin tone and texture of the cheek tissue are similar to that of the nose. In addition, the proximity of the nasolabial fold to the nose facilitates easy transposition. [3,4]

We used this flap for the reconstruction of defect after excision of an ulcerated malignant lesion of the nasal ala involving the alar cartilage. [Figure 1,2] A sublabial flap may also be used if lip reconstruction is needed along. [Figure 6]

\section{Forehead Transposition Flap}

Based on the medial brow area, this vascular flap is pedicled on supratrochlear artery. Advantages of this flap include a good color match, inconspicuous donor and recipient site scars and normal nasal contours. [5]

We used this flap for pigmented lesion near the medial canthus which was completely excised and defect reconstructed. [Figure 3] Trapezoid VY advancement flap or the Reigers flap may also be suitable for such a lesion. [Figure 6]

\section{Rintala Flap}

It is a superiorly based midline flap dissected on supraperiosteal plane. It has been seen to be excellent for reconstruction over the glabella and the entire nasal dorsum upto the nasal tip, even upto the upper part of columella. It offers a good tissue coverage and flap viability, color match, and nasal contour. [6,7] This flap was used for the reconstruction of the nasal dorsum after removal of black pigmented ulcer on the midline dorsum. [Figure 4,5]

\section{Conclusion}

Being ENT surgeons we commonly deal with such lesions on the face like basal cell carcinoma, malignant melanoma, etc which are amenable to complete excision with wide 


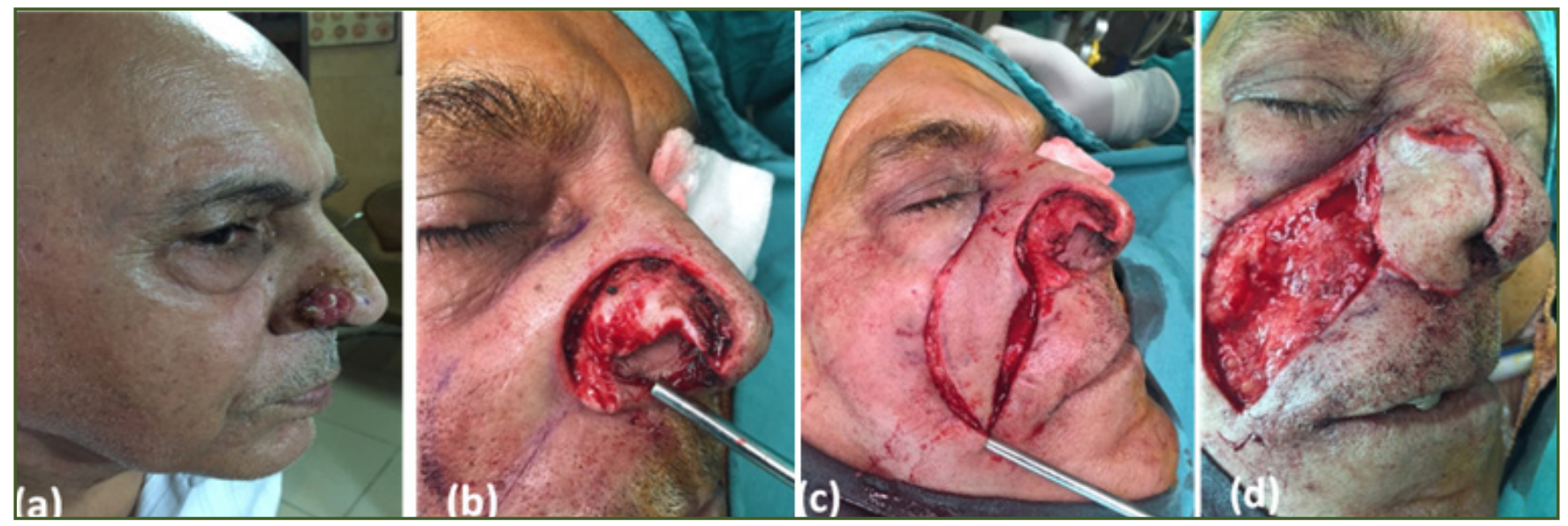

Fig. 1: (a) ulcerated lesion on right nasal ala, (b) excising the lesion, (c) raising the nasolabial flap, (d) covering the primary defect.

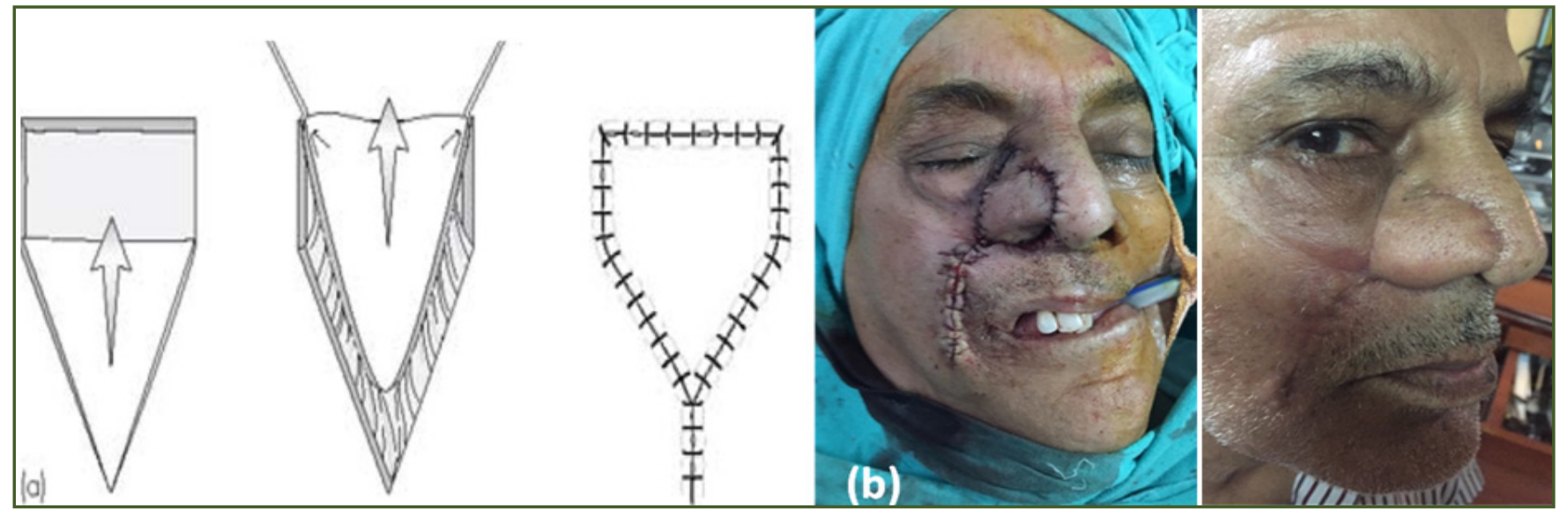

Fig. 2: (a) principle of VY advancement, (b) complete closure of defect, (c) patient at three month follow up.
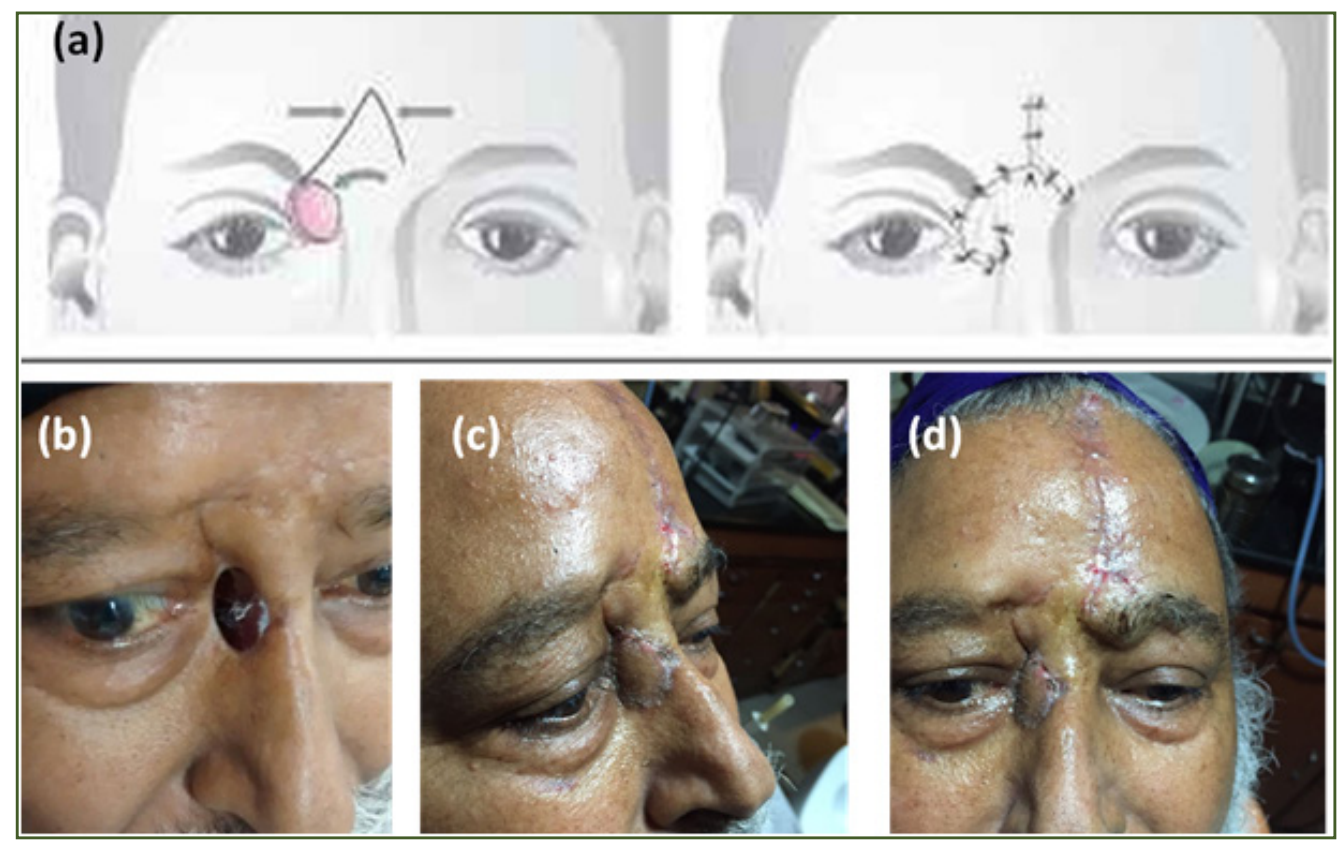

Fig. 3: (a) outline of forehead flap, (b) pigmented lesion, (c,d) final outcome at three weeks. 


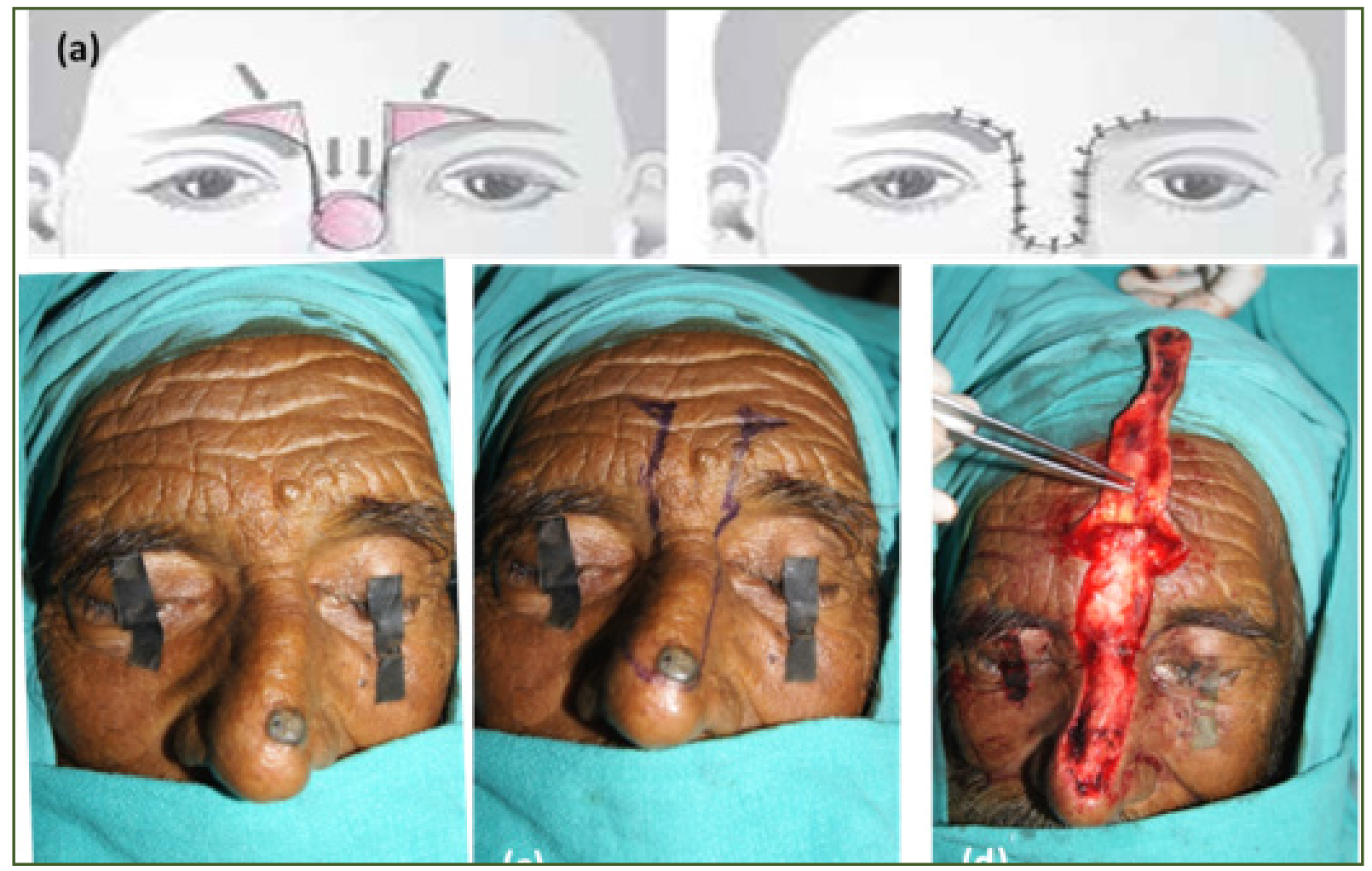

Fig 4: (a) outline of rintala flap with burrow triangle, (b) pigmented ulcer on lower third of nasal dorsum, (c) rintala flap marked along with burrow triangle, (d) flap dissected and raised.

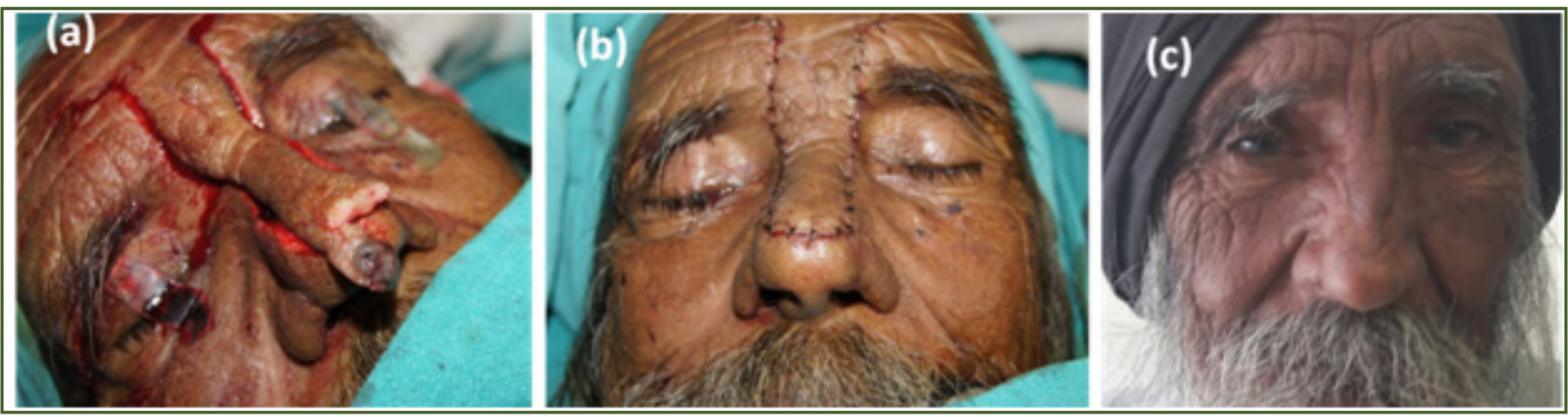

Fig 5: (a) lesion excised, (b) final closure, (c) patient at six month follow up.

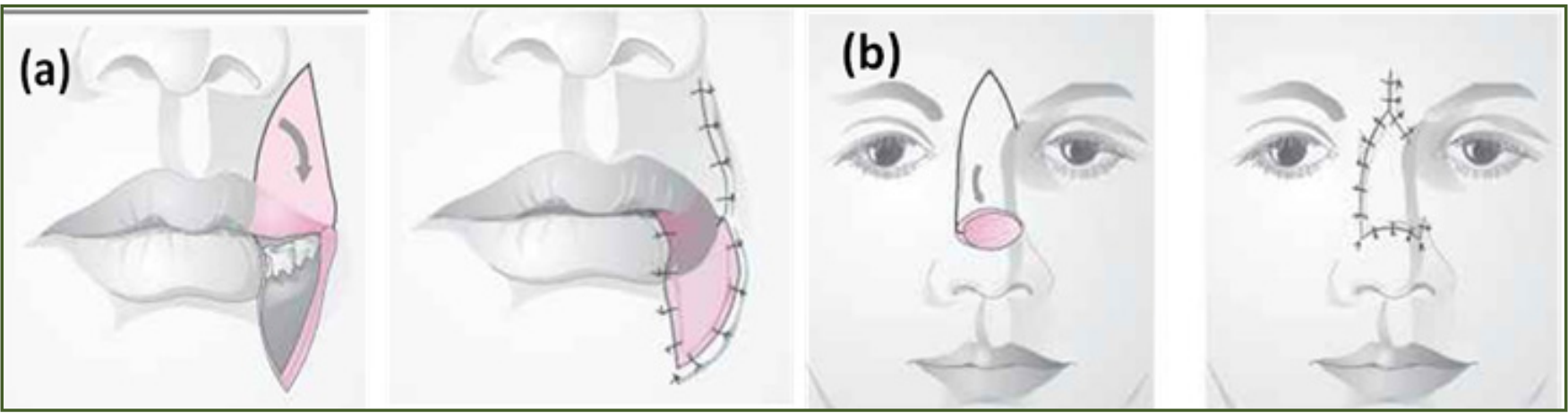

Fig. 6: schematic diagram showing the outline of (a) sublabial flap for lower lip reconstruction, (b) reiger flap for nasal dorsal lesions. 
tissue margins. All that is required is a good reconstruction of the defect after excision. These simple flaps can be easily mastered and utilized as and when required. With this we can limit the Plastic Surgeons being involved in the case and thus avoid additional cost to the patient.

\section{Acknowledgments}

We are thankful for the assistance provided by the Anasthesia team and operating room staff

\section{Conflict of interest:}

all authors declare no conflict of interest

\section{References}

1. Rogers BO. The historical evolution of plastic and reconstructive surgery. Wood-Smith D, Porowski O, eds. Nursing Care of the Plastic Surgery Patient. 1967
2. Principles and Techniques of Nasal Reconstruction; Updated: Jul 24, 2015 Author: Joseph Fata http://emedicine. medscape.com/article/1820512-overview:

3. Thornton J, Griffin J, Constantine F. Nasal Reconstruction: An Overview and Nuances.; Semin Plast Surg. 2008 Nov; 22(4): 257-68.

4. William M. Weathers, MD, Erik M. Wolfswinkel. Expanded Uses for the Nasolabial Flap; Semin Plast Surg. 2013 May; 27(2): 104-109.

5. Stephen S Park. Forehead Flaps Treatment \& Management. Updated: Apr 06, 2015 http://emedicine.medscape.com/ article/880171-treatment\#d15

6. Chiu LD, Hybarger CP, Todes-Taylor N. The Rintala flap revisited. Plast Reconstr Surg. 1994 Nov;94(6):801-7

7. Kiyoshi O, Emi O. The Rintala flap: a versatile procedure for nasal reconstruction. American journal of otolaryngology; 2014;35:549-688

*Corresponding author:

Dr Archana Arora, 159-C rishi nagar, Ludhiana-141001. Punjab, India

Phone: +919888780218

Email: Drarchana.ent@gmail.com 